\title{
Towards unravelling Wolbachia global exchange: a contribution from the Bicyclus and Mylothris butterflies in the Afrotropics
}

\author{
Anne Duplouy ${ }^{1,2^{*}}$ (D), Robin Pranter ${ }^{1}$ (D), Haydon Warren-Gash ${ }^{3}$, Robert Tropek ${ }^{4,5}$ (D) and Niklas Wahlberg ${ }^{1}$ (D)
}

\begin{abstract}
Background: Phylogenetically closely related strains of maternally inherited endosymbiotic bacteria are often found in phylogenetically divergent, and geographically distant insect host species. The interspecies transfer of the symbiont Wolbachia has been thought to have occurred repeatedly, facilitating its observed global pandemic. Few ecological interactions have been proposed as potential routes for the horizontal transfer of Wolbachia within natural insect communities. These routes are however likely to act only at the local scale, but how they may support the global distribution of some Wolbachia strains remains unclear.

Results: Here, we characterize the Wolbachia diversity in butterflies from the tropical forest regions of central Africa to discuss transfer at both local and global scales. We show that numerous species from both the Mylothris (family Pieridae) and Bicyclus (family Nymphalidae) butterfly genera are infected with similar Wolbachia strains, despite only minor interclade contacts across the life cycles of the species within their partially overlapping ecological niches. The phylogenetic distance and differences in resource use between these genera rule out the role of ancestry, hybridization, and shared host-plants in the interspecies transfer of the symbiont. Furthermore, we could not identify any shared ecological factors to explain the presence of the strains in other arthropod species from other habitats, or even ecoregions.
\end{abstract}

Conclusion: Only the systematic surveys of the Wolbachia strains from entire species communities may offer the material currently lacking for understanding how Wolbachia may transfer between highly different and unrelated hosts, as well as across environmental scales.

Keywords: Symbiosis, Vertical transmission, Horizontal transfer, Phylogeny, Lepidoptera, Interspecific interactions

\section{Background}

The maternally inherited endosymbiont Wolbachia is present in more than $20 \%$ of all insect species, making this bacterium one of the most successful organisms on Earth [1-3]. Although host-Wolbachia co-divergence is relatively common between Nematode hosts and their Wolbachia strains, similar examples of co-divergence

\footnotetext{
*Correspondence: anne.duplouy@helsinki.fi; anne.duplouy@biol.lu.se

'Department of Biology, Lund University, Lund, Sweden

${ }^{2}$ Organismal and Evolutionary Biology Research Programme, The University of Helsinki, Helsinki, Finland

Full list of author information is available at the end of the article
}

between insect hosts and their Wolbachia strains remain scarce $([4,5]$, but see [6]). These patterns thus suggest that Wolbachia may have jumped horizontally between host species throughout the $\sim 400$ million years of the symbiont evolutionary history [5, 7-10]. Hybridization events, followed by introgression between closely related species have been shown to support the interspecies transfer of various genetic entities, including Wolbachia [11-13]. Although recent common ancestry is an obvious reason to why two species can carry the same symbionts, studies have shown that it is not the only one (Fig. 1). 


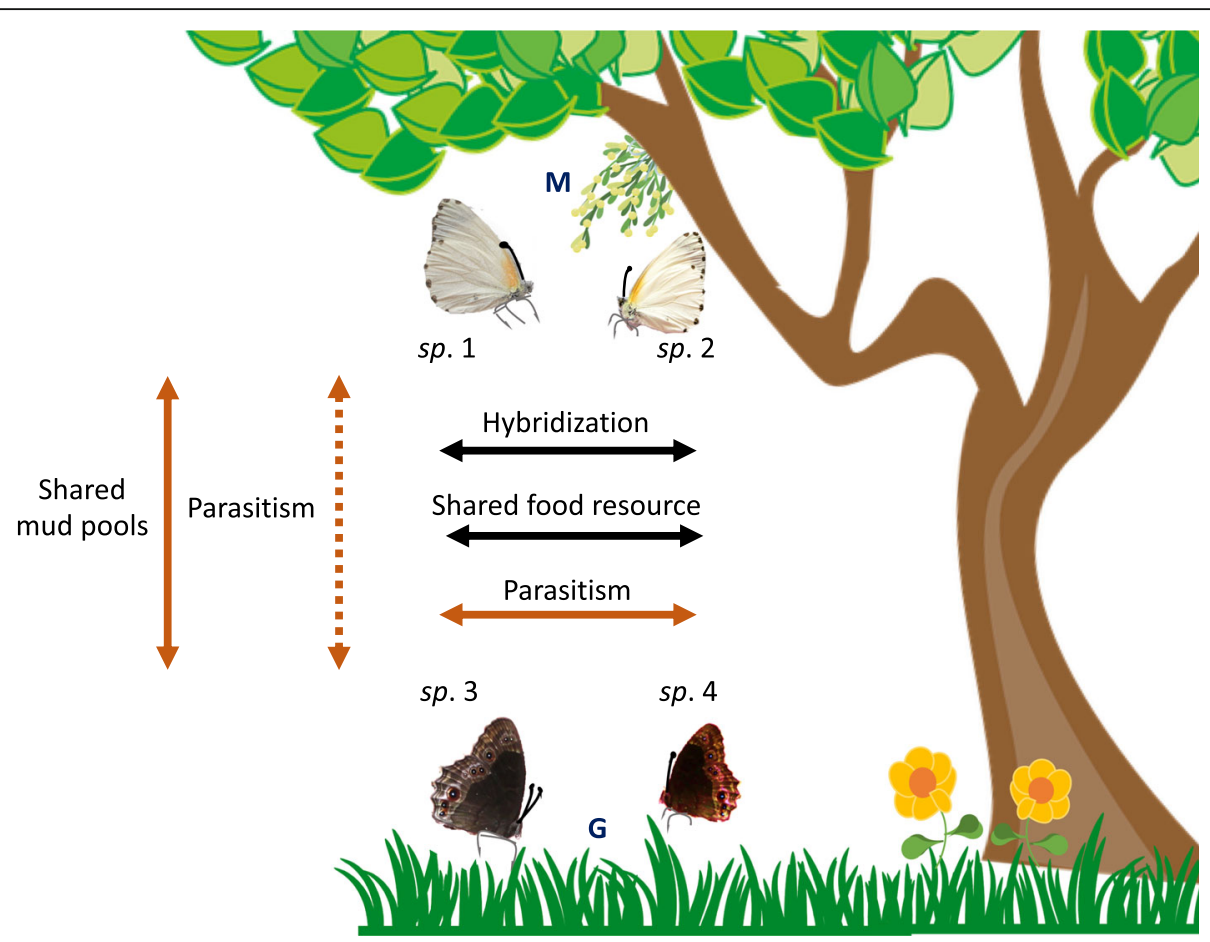

Fig. 1 The micro-habitat of the Mylothris and Bicyclus butterflies in an African tropical forest habitat, and the diverse potential routes of transfer of Wolbachia between and within the butterfly species. In orange the routes that remain to be fully tested, with unlikely routes in dashed lines. (M): Mistletoe, the host-plant of Mylothris butterflies, and (G): Grass, the host-plant of Bicyclus butterflies. Butterfly images modified from pictures by authors HWG and RT

Various ecological interactions between hosts appear to support the horizontal transfer (HT) of Wolbachia between highly divergent species. Through the study of Diptera associated with fleshy mushrooms, Stahlhut et al. [14] suggested that the HT through species hybridization occurs between species of this community, but that shared food-resources may also provide an efficient support for the horizontal movement of the bacterium between divergent host species. Similar conclusions were drawn from the study of an insect community feeding on pumpkin plants [15]. Analogously, an investigation of the Wolbachia infection status of parasitoid wasps showed that the wasps can act as both vectors and hosts for Wolbachia, as the parasitoids were found to carry similar Wolbachia strains as those found in their hosts [16, 17], and as those found in the other parasitoid species feeding on the same hosts [7]. Although exploring each potential transfer route independently is informative $[9,18,19]$, the distribution of Wolbachia in the host phylogeny is likely to be the result of a combination of both the host cladogenesis, and diverse horizontal transfer events between host species, the mechanisms of which yet remain to be characterized. Investigating horizontal movements of the endosymbiont between a wider diversity of host species, including species sharing micro or macro-niches, will increase our understanding of the diverse routes used for the HT of Wolbachia, and thus broaden our understanding of this symbiont's global success.

Butterflies in the genera Mylothris and Bicyclus seem to be an ideal model for studying of the inter-clade transfer of Wolbachia. The two genera (belonging to the families Pieridae and Nymphalidae, respectively) have diverged from each other about $97 \mathrm{My}$ ago [20]. They represent two of the most species-rich genera of African butterflies, each including about 100 species [21, 22]. Both Mylothris and Bicyclus butterflies share similar geographical distributions, covering the Afrotropical region [23-25]. They include specialists for the same types of macro-habitats, from primary forests to forest edges and savannah grasslands [26, 27]. However, despite the syntopic occurrence of many species, the two genera mostly differ in the micro-habitat use. Most distinctively, they inhabit different vertical layers of the habitat [27]. The Mylothris species often prefer higher strata [27], where their larval host-plants (mistletoes mostly from Loranthaceae and Santalaceae families) occur [28-30], while the Bicyclus species occur predominantly in the undergrowth of the habitat [27], around their grassy larval host-plants (mostly Poaceae family, but sometimes Marantaceae or Zingiberaceae) [31, 32]. The two clades differ also in their adult food resources. Whilst Mylothris 
butterflies are commonly nectaring on various plant species (Tropek, unpublished data), Bicyclus are mostly fruit-feeders and sap-suckers and are observed on flowers only occasionally [33, 34]. On the other hand, species from both clades are observed mud-puddling, during which they could interact.

Prior to this study, Mylothris agathina was possibly the only Mylothris species to be known to carry Wolbachia [35, 36]. Earlier, Poulton [37] described an allfemale brood in a species he referred to as M. spica, in Cameroon. This particular phenotype could be suggestive of an infection with a sex-ratio distorting Wolbachia strain, similar to the ones infecting Acraea encedon, A. encedana [13], or Hypolimnas bolina [38], but this has yet to be fully tested. In contrast, a recent study showed that at least 19 Bicyclus species carry Wolbachia [39]. Many of the strains characterized in the divergent Bicyclus species shown high genetic similarity [39], and were also similar to strains described earlier in various insects, including Lepidoptera, from other geographic regions [9, 19, 40]. These patterns are suggestive of the horizontal acquisition of the bacterium between Bicyclus species, though the mechanisms of the transfers remained unclear.

We predicted that butterflies belonging to the same genus could share similar strains of Wolbachia due to recent common ancestry, and the possibility of HT by the means of hybridization events and shared larval host-plants. We did not expect the same to be true between the two host genera, as the hybridization between individuals of different families is impossible, and as the two genera studied here do not share micro-habitats (as stated above). To further looked at the potential role of geographic distribution and habitat on any particular ecological routes to the transfer of the symbiont between species, we included Wolbachia strains previously characterized from any Lepidoptera, any Hymenoptera (many of which could be parasitoid species of Lepidopteran larvae), and any other African arthropods, to the analyses. Finally, we call upon the investigation of more insect communities across the globe, and upon the revision of the current MLST-based Wolbachia strain and strain-type (ST) characterization method.

\section{Results}

\section{Wolbachia screening and strain diversity}

Out of the 225 Mylothris butterflies screened, 70 specimens $(31 \%)$ were found infected with Wolbachia, representing 23 of the 53 species $(43 \%)$ included in the study. Similarly, 15 out of the 63 Bicyclus specimens (24\%), representing 10 out of 21 species (47.5\%) screened, were infected with Wolbachia. This brings the total number of Bicyclus species known to carry Wolbachia to 23 (19 described by [39], and four new ones in the present study). One of the two Aphysoneura scapulifascia specimens included in this study was also found to host Wolbachia, while the three Brakefieldia peitho specimens were uninfected. We successfully sequenced between three and six Wolbachia markers for 66 of the 86 butterflies (77\%) found infected with the symbiont.

There was a higher detectable diversity of Bsupergroup than A-supergroup Wolbachia strains in the Mylothris and also in the Bicyclus butterflies (Fig. 2, S1, and S2, and Table S1, Table S2). Most of the infected specimens were infected with B-supergroup Wolbachia $\left(\mathrm{N}_{\text {Mylothris }}=57 ; \mathrm{N}_{\text {Bicyclus }}=13 ; \mathrm{N}_{\text {Aphysoneura }}=1\right.$, or $81.5,87$ and $100 \%$ respectively), while the other infected specimens carried A-supergroup Wolbachia. Our analyses suggested that the strains clustered within two divergent A-supergroup strains (A1 and A2), and four Bsupergroup strains (B1-B4), some belonging to the Strain-Type ST-19, ST-40, ST-108, ST-187, and ST-423 (Fig. 2) [39], and other STs not yet characterized in the pubMLST-Wolbachia. However, the Bicyclus and Mylothris species studied here did not carry any strain of the ST-41, which was previously suggested as highly common in Lepidoptera $[9,40]$. The host species $M$. uniformis, M. yulei, and M. asphodelus were found to carry two infections, each as single infection (i.e. different specimens of the same species carry different Wolbachia strains); and we suggest multiple infections in five butterflies (2x M. agathina and 3x M. bernice), as double peaks in the chromatogrammes from these specimens were observed, even after repeating sequencing on independent PCR products. Finally, the sequencing failed for two Wolbachia-infected samples (HWG1_176: $M$. crawshayi, and HWG1_211: M. asphodelus; Table S1), which has not allowed us to conclude on the identity of the infection in these specimens.

\section{Wolbachia host specificity}

From our dataset, there was no effect of cladogenesis on whether two species carry similar Wolbachia strains, with no pattern of co-evolution between the butterflies and their respective infections (Fig. 2). For example, The Wolbachia strain variants 'B4' (Fig. 2) are found in species from at least five divergent Bicyclus species-groups, including the evadne-group, the saussurei-group, the angulosa-group, the trilophus-group and the hewitsonigroup [41]. Additionally, many of the Wolbachia strains characterized in the Mylothris butterflies (family Pieridae, in blue in Fig. 2) were similar to those from the Bicyclus butterflies (family Nymphalidae, in blue in Fig. 2) [39] (Table S3), and to some from other Lepidoptera, or other insects (Figure S3).

Finally, we could not detect any clustering of the strains based on their host habitats (i.e. open savannah versus forest) (Fig. 2, S1, and S2), nor based on their 


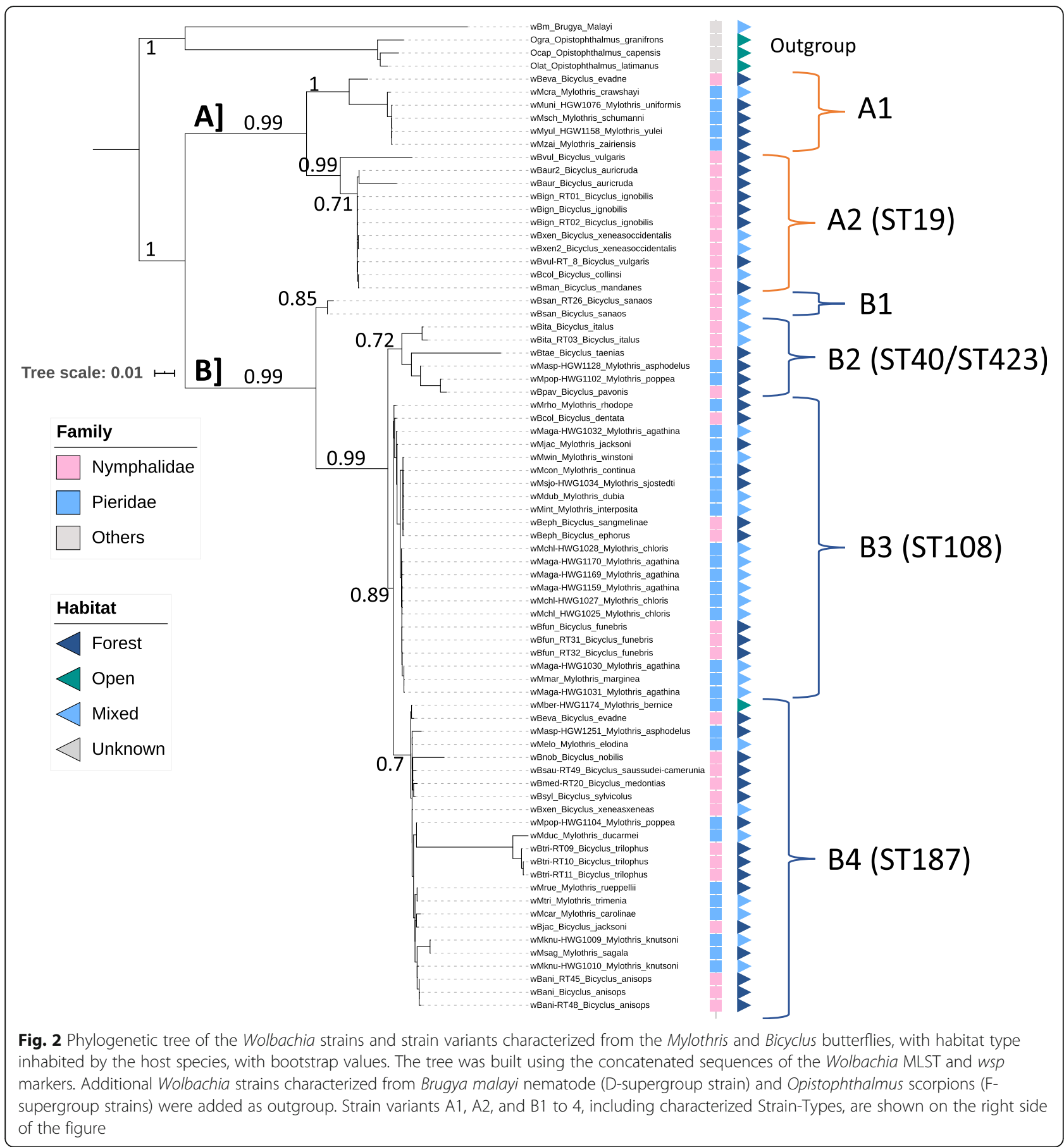

host ecoregions (e.g. Afrotropics versus Oceania) (Figure S3). Strong biases however occur in the dataset used for the present study. There were for example very few Wolbachia strains characterized from host species evolving in certain ecoregions available in the PubMLST-Wolbachia database, especially from the Neotropics or the Nearctics. Additionally, the dataset is incomplete (i.e. missing data about habitats of the Hymenoptera species).

\section{Discussion}

We predicted that butterflies belonging to the same genus would share similar strains of Wolbachia due to recent common ancestry, and the possibility of HT by the means of hybridization events, and/or shared resources. We did not expect the same to be true between genera as any hybridization is impossible, and the butterflies of the two genera considered in this study only share similar macro-habitats (i.e. forest and open 
savannah), but not micro-habitats (i.e. larval host-plant). Our data did not support co-cladogenesis of Wolbachia in the African butterflies, but still partially supported the first prediction. Within each genus, many species carry similar strains to the one found in congeneric species, but not always. However, the same was also true between genera, which contrasts with our second prediction. The occurrence of similar Wolbachia strains in both of the two Lepidoptera families (Pieridae and Nymphalidae) is unlikely to occur through shared ancestry, nor through horizontal transfer via the larval hostplants. This is in a clear contrast with the insect communities associated with fleshy mushrooms [14], and pumpkin plants [15]. These results suggest that factors other than the larval host-plants must support the transfer of Wolbachia between host species. The study of the horizontal transfer of Wolbachia between host species might however be currently skewed by (1) our restricted knowledge of the ecology of each species within insect communities, (2) the strong biases associated with the available Wolbachia strain diversity dataset, and (3) the way we characterize the different strains of the bacterium.

As it is the case for many species, especially in the Afrotropics, many aspects of the ecology of the Mylothris and Bicyclus butterflies remain unfortunately poorly studied. To date, almost all ecological studies of the Mylothris butterflies focus on their association at the larval stage to mistletoe plants (e.g. Santalaceae family) $[28-30,42]$ in their native Afrotropical range [23-25], neglecting other aspects of their life history. There is currently no available comprehensive record, or formal study looking at the community of parasitoid wasps or mite communities associated with any Mylothris or Bicyclus butterflies. To our knowledge, Gupta et al. [43] provided the only description of Cotesia pistrinariae as a parasitoid wasp of $M$. chloris; but it remains unknown whether C. pistrinariae could also parasitize any Bicyclus species, or vector Wolbachia between insect hosts. Our phylogenetic tree suggests several examples of parasitoid wasps sharing similar infection to Bicyclus or Mylothris butterflies, however in each case the direct contact between the Hymenoptera and the Lepidoptera species are unlikely [9], due to geographical or ecological reasons, or both. For example, despite sharing similar Wolbachia strains, the braconid parasitoid wasp Apanteles chilonis, an endoparasitoid of the rice stem borer Chilo suppressalis [44] in the Palearctic, is unlikely to parasitize $B$. vulgaris or B. auricruda in the Afrotropics. Similarly, Evania appendigaster, a parasitoid of cockroaches [45], is also unlikely to predate on B. ignobilis or B. xeneas. Only systematic surveys of the Wolbachia strains from species communities, rather than individual species or clades, could potentially offer the material currently lacking for testing how a single strain of Wolbachia may occur in highly different hosts and environments. Investigating the Wolbachia infection status of the community of endo- and ectoparasites associated with the Bicyclus and Mylothris butterflies, should thus inform whether these parasites can act as vectors of Wolbachia among the two genera of butterflies, as it was previously suggested in other insects, including flies, mosquitoes and ants $[7,19,46]$.

Wolbachia is known to survive in an extracellular phase in the laboratory for up to a week [47]. Although Mylothris and Bicyclus larvae use very different hostplants and adult food resources [48, 49], the adult butterflies of both genera have occasionally been observed sucking from the same mud-pools or animal feces. By potential being the only nutrient resources shared by the two genera (Tropek, pers. comm.), mudpools and feces could thus represent suitable short-term environments supporting the survival of Wolbachia until its successful horizontal transfer to a new host niche. This, however, remains to be tested.

Although the origin of Wolbachia supergroups A and B is estimated to be 200 My ago (based on whole genome data, [50]), the divergence of the strains within each supergroup is most likely much younger (e.g. estimated around 28 My ago by Ahmed et al. [9] based on the MLST markers only), and does not match the divergence between Pieridae and Nymphalidae butterflies (97 My ago, [20]). This further support our claim that cocladogenesis is improbable, and strains have not been passed down from their common ancestor or transferred via hybridization events between the butterfly species. Additionally, the ecological links described so far as potential routes for the recent transfer of Wolbachia between species can only explain local HTs of the bacterium. Nonetheless, Ahmed et al. [9] found that strain type ST-41, a strain type commonly characterized in butterflies $[9,40]$, was found in species from Africa (i.e. Azanus mirza; Lycaenidae), Japan (i.e. Eurema hecabe; Pieridae), Borneo (i.e. Nacaduba angusta; Lycaenidae) and North America (i.e. Celastrina argiolus; Lycaenidae). Following these results, we show that Mylothris and Bicyclus butterflies in Africa share similar Wolbachia strains to, for example, Lycaenidae from South Africa (with ST-19) or Malaysia (with ST-40) [9], or moths from the Pacific islands [51], and potentially to many other species in between these two geographical regions. None of the geographically distant host species described in these two studies are likely to share the same host-plants, parasitoids nor mite parasites. Despite the lack of a clear understanding of 'how', the research community however agrees that the ability of Wolbachia to transfer horizontally has without a doubt contributed to the global pandemic of the bacterium [52]. 
A recent study by Detcharoen et al [53] estimated that, to date, more than $99 \%$ of all existing Wolbachia strains have yet to be characterized; worse: that strong biases occur in the database. The PubMLST-Wolbachia database [18] currently includes over 2000 strains. Out of those, 370 are from Lepidoptera species (18.3\%), which is more than for the Coleoptera (92; 4.6\%), the Hemiptera $(297 ; 14.7 \%)$, and the Hymenoptera $(359 ; 17.8 \%)$, but less than the Diptera (473; 23.4\%). Thus, strains from particular insect orders, but also host families are more represented. Furthermore, in Lepidoptera for example, most of the Wolbachia strains were characterized from species inhabiting the Palearctic ecoregion $(N=107 ; 29 \%)$, while very few are from the Afrotropics $(N=18 ; 5 \%)$. And this pattern at the ecoregion level is similarly found in the other insect orders, representing another important bias in the PubMLST-Wolbachia database. Although the present study brings new data for the Afrotropic region, showing for example that the ST-41 commonly found in Lepidoptera [9], is not found in the Mylothris and Bicyclus, many biases still remain, and they will continue to impede the comprehensive study of the diversity and geographical distribution of Wolbachia strains, as well as our understanding of the mechanisms behind their pandemic.

The commonly applied method to characterized Wolbachia strains is based on the sequences of six markers for a maximum length of about $3000 \mathrm{bp}$ [18]. This molecular technique has recently been highly criticized [54]. New studies are pushing towards the use of whole genome data, which seems to more accurately infer Wolbachia supergroup phylogeny and origin $[50,55]$. Although still rather expensive, whole genome sequencing can not only provide the material to improve our understanding of Wolbachia strain diversity, its diversification rates, and its $\mathrm{HT}$, but can also support the investigation of the ecology and evolution of the bacterium, including for example its ability to modify its host phenotype [56], and maybe, one day, its ability to establish in a wide range of host species.

The horizontal transfer of Wolbachia between insect hosts was already suggested in the early 90's [57, 58]. Our study contributes to the growing literature showing that ecological links between species can act as platforms to the between species transfer of the symbiont, however no common understanding of this process and the relative importance of each transfer route has yet been proposed. Furthermore, our study also re-enforces the idea that biases in the dataset, and restrictions in the methodological approaches associated with such study, will, until solved, continue to impede our comprehensive analyses and understanding of the global Wolbachia pandemic.

\section{Methods \\ Material}

All Mylothris specimens used in this study originated from the private collections of Haydon Warren-Gash and Robert Ducarme, and from the African Butterfly Research Institute 'ABRI' holding, which were collected under various local collection permits. All Bicyclus, Aphysoneura and Brakefieldia specimens were collected under research permits from the Cameroonian government to Dr. Robert Tropek. Tissue material from 225 adult butterflies from 53 Mylothris species [22], 63 specimens from 21 Bicyclus species, two specimens of Aphysoneura scapulifascia, and three specimens of Brakefieldia peitho were included in the present study. The sample size for each species, and country of origin of each specimen can be found in the document available from Zenodo (doi:https://doi.org/10. 5281/zenodo.3934112).

\section{Habitats and ecoregions}

The world's terrestrial lands have been divided in eight biogeographic realms, which delineations do not follow countries boundaries, but are defined by the evolutionary history of the organisms they contain $[59,60]$. The eight biogeographic realms, here called ecoregions for simplicity, are (1) Afrotropic (Trans-Saharan Africa and Arabia), (2) Antarctic, (3) Australasia (Australia, NewGuinea, and New Zealand), (4) Indo-Malay (Indian subcontinent Southeast Asia and Southern China), (5) Nearctic (North America), (6) Neotropic (South and Central America and the Caribbean), (7) Oceania (South Pacific islands), and (8) Palearctic (Eurasia and North Africa) [60]. Each of these ecoregion covers a wide diversity of biomes, or habitats. The Mylothris and Bicyclus butterflies evolve only within the Afrotropical region [23-25], but different species are found from either dense primary forests (i.e. forest habitat), forest edges (i.e. mixed habitat), or open savannah grassland habitats (i.e. open habitat) (Fig. 2) [61].

\section{Molecular work}

DNA was extracted from legs from each butterfly following the protocol of a Qiagen DNeasy Blood \& Tissue Extraction Kit (Qiagen, USA). We screened all specimens for Wolbachia, using Wolbachia specific primers amplifying the wsp gene $(81 \mathrm{~F} / 691 \mathrm{R},[62])$, and three to five of the Wolbachia Multi Locus Sequence Typing markers (MLSTs, [18]). All sequences were aligned and manually curated in Geneious R11.0 (http://www.geneious.com, [63]), and submitted to GenBank under the accession codes: MT669957-70007 \& MT782897-3039.

\section{Genetic data from additional Wolbachia strains}

In order to (I) identify whether the sequences from the Wolbachia characterized from our butterfly samples 
were unique or not to their host species, and (II) characterize any potential route of transfer of the strains between species (Fig. 1), we fished out the sequences of the wsp and MLST markers, from all Lepidoptera, all Hymenoptera, and all other African arthropods that were available from the PubMLST-Wolbachia database by December 2019 [18]. Many of the records from this database were from specimens of the same species and the same population, we thus randomly deleted some of the duplicates to keep a maximum of three of each type. Additionally, we included all wsp and MLSTs sequences from Wolbachia strains previously characterized from Bicyclus species [39] (GenBank IDs: KY658538-52, KY658652, KY658655, and KY658572-90), and those from Malagasy dung beetles [11] (GenBank IDs: MK636654-66), that are not present in the PubMLSTWolbachia database. The full list of specimens and sequences included in this study can be retrieved from Zenodo (doi: https://doi.org/10.5281/zenodo.3934112).

\section{Phylogenetic analyses}

The sequences of the six Wolbachia markers were concatenated in the following order: $\operatorname{cox} A, f b p A, f t s Z$, gat $B$, $h c p A$, and $w s p$, for a maximum alignment of $3149 \mathrm{bp}$. Each tree was built in CIPRES [64] using RAxML-XSEDE [65] with the Gamma+I parameter. Tree visualization and figures were done with FigTree (http://tree.bio.ed.ac.uk/ software/figtree/) and ITOL $[66,67]$ using the bipartitions output trees produced by RAxML.

\section{Supplementary information}

Supplementary information accompanies this paper at https://doi.org/10. 1186/s12866-020-02011-2.

Additional file 1: Table S1: Divergence rate (\%) of the wsp marker between the 11 Wolbachia strains and strain variants characterized from Mylothris butterfly species. A-supergroup Wolbachia strains are shown in pink, B-Wolbachia in blue. Inside cell colors vary in accordance with degree of similarity (white: less than 75\% similarity, gray: between $75 \& 97 \%$ similarity, dark-gray: more than $97 \%$ similarity). Table S2: Divergence rate (\%) of the wsp marker between the 14 Wolbachia strains and strain variants characterized from Bicyclus butterfly species (as characterized in this study and by (Duplouy and Brattstrom [39])). A-supergroup strains are shown in pink, B-Wolbachia in blue. All variants share the same color. Inside cell colors vary and in accordance with degree of similarity (white: less than $75 \%$ similarity, gray: between 75 \& 97\% similarity, dark-gray: more than $97 \%$ similarity). Table S3: Divergence rate (\%) between the Wolbachia strains and strain variants characterized from the Mylothris butterflies and the Bicyclus butterflies (as characterized in this study and by (Duplouy and Brattstrom [39])). Central cells colored in accordance with degree of similarity between strains (white: less than $75 \%$ similarity, gray: between 75 and 97\% similarity, dark-gray: more than 97\% similarity). Figure S1: Rooted phylogenetic relationships of the concatenated MLST and wsp genes sequences from the different Wolbachia characterized from the Mylothris butterflies, with bootstrap values. Additional Wolbachia strains characterized from Brugya malayi (D-supergroup strain) and from Opistophthalmus scorpions (F-supergroup strains) were added as outgroup. Habitat of the host is shown in right-circle. Figure S2: Rooted phylogenetic relationships of the concatenated MLST and wsp genes sequences from the Bicyclus butterflies, with bootstrap values. Additional
Wolbachia strains characterized from Brugya malayi (D-supergroup strain) and from Opistophthalmus scorpions (F-supergroup strains) were added as outgroup. Habitat of the host is shown in right-circle. Figure S3: Phylogenetic tree of all available Wolbachia strains and strain variants characterized from Lepidoptera, Hymenoptera, and all other African arthropods. The tree was built using the concatenated sequences of the Wolbachia MLST and wsp markers. Colored squares, circles and triangles on the right provide the family, ecoregion and habitat of the hosts, respectively. Dataset includes strains described in the present study, as well as strains from Bicyclus butterflies as in [39], from Malagasy Nanos dungbeetles as in [1 1], and all pubMLST-registered strains from Lepidoptera, Hymenoptera and African arthropods [18]. Wolbachia strains characterized from Brugya malayi nematode (D-supergroup strain) and from Opistophthalmus scorpions (F-supergroup strains) were used as outgroup.

\section{Abbreviation}

ST: Strain Type

\section{Acknowledgements}

We would like to thank Dr. A. Chiocchio and the members of the Systematic Biology Group at the Lund University for fruitful discussions. Thanks to A. Giraud for contributing to the molecular work in the lab, and to R.K. Sahoo for helpful suggestions on illustration software.

\section{Authors' contributions}

$A D, R P \& N W$ conceived the study. AD analyzed the data and wrote the manuscript. All authors contributed to data collected, and all authors reviewed and agreed on the manuscript.

\section{Funding}

AD was funded by a Marie Curie Sklodowska Individual Fellowship to $A D$ (\#790531, HostSweetHome) and by the Academy of Finland to AD (\#1328944). RT was funded by the Charles University (PRIMUS/17/SCI/8 and UNCE204069) and the National Geographic Society (Waitt Grant W163-11). NW was funded by a grant from the Swedish Research Council (grant no. 2015-04441). Open Access funding provided by Lund University.

\section{Availability of data and materials}

The dataset supporting the conclusions of this article is available in the Zenodo repository, https://zenodo.org/record/3934112\#.X1YrqIBS_BI.

Ethics approval and consent to participate Not applicable.

\section{Consent for publication}

Not applicable.

\section{Competing interests}

The authors declare no conflict of interests.

\section{Author details}

${ }^{1}$ Department of Biology, Lund University, Lund, Sweden. ${ }^{2}$ Organismal and Evolutionary Biology Research Programme, The University of Helsinki, Helsinki, Finland. ${ }^{3}$ Overstrand Mansions, Prince of Wales Drive, London SW11 4EU, UK. ${ }^{4}$ Department of Ecology, Faculty of Science, Charles University, Prague, Czech Republic. Institute of Entomology, Biology Centre of the Czech Academy of Sciences, Ceske Budejovice, Czech Republic.

Received: 15 July 2020 Accepted: 14 October 2020

Published online: 20 October 2020

\section{References}

1. Hilgenboecker K, Hammerstein P, Schlattmann P, Telschow A, Werren JH. How many species are infected with Wolbachia? A statistical analysis of current data. FEMS Microbiol Lett. 2008;281(2):215-20. https://doi.org/10. 1111/j.1574-6968.2008.01110.x.

2. Zug R, Hammerstein P. Still a host of hosts for Wolbachia: analysis of recent data suggests that $40 \%$ of terrestrial arthropod species are infected. PLoS One. 2012;7(6):e38544. https://doi.org/10.1371/journal.pone.0038544. 
3. Weinert LA, Araujo-Jnr EV, Ahmed MZ, Welch JJ. The incidence of bacterial endosymbionts in terrestrial arthropods. Proc Biol Sci. 2015;282(1807): 20150249. https://doi.org/10.1098/rspb.2015.0249.

4. Raychoudhury R, Baldo L, Oliveira DC, Werren JH. Modes of acquisition of Wolbachia: horizontal transfer, hybrid introgression, and codivergence in the Nasonia species complex. Evolution. 2009;63(1):165-83. https://doi.org/10. 1111/j.1558-5646.2008.00533.x.

5. Bordenstein SR, Paraskevopoulos C, Dunning Hotopp JC, Sapountzis P, Lo N, Bandi C, et al. Parasitism and mutualism in Wolbachia: what the phylogenomic trees can and cannot say. Mol Biol Evol. 2009;26(1):231-41. https://doi.org/10.1093/molbev/msn243.

6. Balvin O, Roth S, Talbot B, Reinhardt K. Co-speciation in bedbug Wolbachia parallel the pattern in nematode hosts. Sci Rep. 2018;8(1):8797. https://doi. org/10.1038/s41598-018-25545-y.

7. Vavre F, Fleury F, Lepetit D, Fouillet P, Bouletreau M. Phylogenetic evidence for horizontal transmission of Wolbachia in host-parasitoid associations. Mol Biol Evol. 1999;16(12):1711-23. https://doi.org/10.1093/oxfordjournals. molbev.a026084

8. Shoemaker DD, Machado CA, Molbo D, Werren JH, Windsor DM, Herre EA The distribution of Wolbachia in fig wasps: correlations with host phylogeny, ecology and population structure. Proc Biol Sci. 2002;269(1506): 2257-67. https://doi.org/10.1098/rspb.2002.2100.

9. Ahmed MZ, Breinholt JW, Kawahara AY. Evidence for common horizontal transmission of Wolbachia among butterflies and moths. BMC Evol Biol. 2016;16(1):118. https://doi.org/10.1186/s12862-016-0660-x.

10. Johannesen J. Tracing the history and ecological context of Wolbachia double infection in a specialist host (Urophora cardui)-parasitoid (Eurytoma serratulae) system. Ecol Evol. 2017;7(3):986-96. https://doi.org/10.1002/ece3. 2713.

11. Miraldo A, Duplouy A. High Wolbachia strain diversity in a clade of dung beetles endemic to Madagascar. Front Ecol Evol. 2019;7. https://doi.org/10. 3389/fevo.2019.00157.

12. Gaunet A, Dincã V, Dapporto L, Matagud S, Vodã R, Schär S, et al. Two consecutive Wolbachia-mediated mitochondrial introgressions obscure taxonomy in Palearctic swallowtail butterflies (Lepidoptera, Papilionidae). Zoologica Scripta. 2019;48(4):507-19. https://doi.org/10.1111/zsc.12355.

13. Jiggins FM. Male-killing Wolbachia and mitochondrial DNA: selective sweeps, hybrid introgression and parasite population dynamics. Genetics. 2003;164(1):5-12.

14. Stahlhut JK, Desjardins CA, Clark ME, Baldo L, Russell JA, Werren JH, et al. The mushroom habitat as an ecological arena for global exchange of Wolbachia. Mol Ecol. 2010;19(9):1940-52. https://doi.org/10.1111/j.1365-294X. 2010.04572.x.

15. Sintupachee $S$, Milne JR, Poonchaisri S, Baimai V, Kittayapong P. Closely related Wolbachia strains within the pumpkin arthropod community and the potential for horizontal transmission via the plant. Microb Ecol. 2006; 51(3):294-301. https://doi.org/10.1007/s00248-006-9036-x.

16. Werren $J H, O^{\prime} N$ Neill SL. The evolution of heritable symbionts. In: $\mathrm{O}^{\prime} \mathrm{Neill} S \mathrm{SL}$, Hoffmann AA, Werren JH, editors. Influential passengers. Oxford: Oxford University Press; 1998. p. 1-41.

17. Ahmed MZ, Li SJ, Xue X, Yin XJ, Ren SX, Jiggins FM, et al. The intracellular bacterium Wolbachia uses parasitoid wasps as phoretic vectors for efficient horizontal transmission. PLoS Pathog. 2015;10(2):e1004672. https://doi.org/ 10.1371/journal.ppat.1004672.

18. Baldo L, Dunning Hotopp JC, Jolley KA, Bordenstein SR, Biber SA, Choudhury RR, et al. Multilocus sequence typing system for the endosymbiont Wolbachia pipientis. Appl Environ Microbiol. 2006;72(11): 7098-110. https://doi.org/10.1128/AEM.00731-06.

19. Shaikevich E, Bogacheva A, Rakova V, Ganushkina L, Ilinsky Y. Wolbachia symbionts in mosquitoes: Intra- and intersupergroup recombinations, horizontal transmission and evolution. Mol Phylogenet Evol. 2019;134:24-34. https://doi.org/10.1016/j.ympev.2019.01.020

20. Chazot N, Wahlberg N, Freitas AVL, Mitter C, Labandeira C, Sohn JC, et al. Priors and posteriors in Bayesian timing of divergence analyses: the age of butterflies revisited. Syst Biol. 2019;68(5):797-813. https://doi.org/10.1093/ sysbio/syz002.

21. Carcasson RH. A preliminary survey of the zoogeography of African butterflies. East Afr Wildlife J. 1964:e:122-57. https://doi.org/10.1111/j.13652028.1964.tb00203.x

22. Warren-Gash H, Aduse-Poku K, Murillo-Ramos L, Wahlberg N. Systematics and evolution of the African butterfly genus Mylothris (Lepidoptera,
Pieridae). Nota Lepidopterologica. 2020;43:1-14. https://doi.org/10.3897/nl. 43.46354 .

23. Seitz A. Die gross schmetterlinge der erde: eine systematishe bearbeitung des bis jetzt bekannten gross schmetterlinge. Stuttgart: Verlag des Seitzschen Werkes (Alfred Kernen); 1907.

24. Picker M, Griffiths C, Weaving A. Field guide to insects of South Africa. New Holland Books (US), 2003. ISBN 9781868727131.

25. Mendes LF. Bivar de Sousa a. description of a new species of Mylothris from northern Angola (Lepidoptera: Pieridae). Bollettino della Soc Entomol Ital. 2009;141(1):55-8.

26. Larsen TB. Butterflies of West Africa. Strenstrup: Apollo Books; 2005.

27. Tropek R, Konvicka M. Forest eternal? Endemic butterflies of the Bamenda highlands, Cameroon, avoid close-canopy forest. Afr J Ecol. 2010;48(2):42837. https://doi.org/10.1111/j.1365-2028.2009.01129.x.

28. Braby MF, Trueman JW. Evolution of larval host plant associations and adaptive radiation in pierid butterflies. J Evol Biol. 2006;19(5):1677-90. https://doi.org/10.1111/j.1420-9101.2006.01109.x.

29. Braby MF. Afrotropical mistletoe butterflies: larval food plant relationships of Mylothris Hubner (Lepidoptera : Pieridae). J Nat Hist. 2005;39(6):499-513. https://doi.org/10.1080/00222930410001708687.

30. Claassens AJM, Dickson CGC. Mylothris chloris agathina (Cramer) (Lepidoptera: Pieridae), a species which has extended its range of distribution from the easterly part of South Africa to the extreme Western cape. Entomologist's Rec J Variation. 1986;98:1-4.

31. Nokelainen O, Ripley BS, van Bergen E, Osborne CP, Brakefield PM. Preference for C4 shade grasses increases hatchling performance in the butterfly, Bicyclus safitza. Ecol Evol. 2016;6(15):5246-55. https://doi.org/10. 1002/ece3.2235

32. Pena C, Wahlberg N. Prehistorical climate change increased diversification of a group of butterflies. Biol Lett. 2008;4(3):274-8. https://doi.org/10.1098/ rsbl.2008.0062.

33. Maicher V, Safian S, Murkwe M, Przybylowicz L, Janecek S, Fokam EB, et al. Flying between raindrops: strong seasonal turnover of several Lepidoptera groups in lowland rainforests of Mount Cameroon. Ecol Evol. 2018;8(24): 12761-72. https://doi.org/10.1002/ece3.4704.

34. Maicher V, Sáfián $S$, Murkwe M, Delabye S, Przybyłowicz L, Potocký P, et al. Seasonal shifts of biodiversity patterns and species' elevation ranges of butterflies and moths along a complete rainforest elevational gradient on Mount Cameroon. J Biogeogr. 2019;47(2):342-54. https:// doi.org/10.1111/jbi.13740.

35. Duplouy A, Hornett EA. Uncovering the hidden players in Lepidoptera biology: the heritable microbial endosymbionts. PeerJ. 2018;6:e4629. https:// doi.org/10.7717/peerj.4629.

36. Russell JA, Funaro CF, Giraldo YM, Goldman-Huertas B, Suh D, Kronauer DJ, et al. A veritable menagerie of heritable bacteria from ants, butterflies, and beyond: broad molecular surveys and a systematic review. PLoS One. 2012; 7(12):e51027. https://doi.org/10.1371/journal.pone.0051027.

37. Poulton EB. An all-female family of Mylothris spica, Moschl. Reared by Miss M.E. Fountaine from a company of larvae at Buea (about $3000 \mathrm{ft}$.) in the Cameroons. In: Proceedings of the Royal Entomological Society of London Series, vol. A 2; 1928. p. 75.

38. Dyson EA, Hurst GD. Persistence of an extreme sex-ratio bias in a natural population. Proc Natl Acad Sci U S A. 2004;101(17):6520-3. https://doi.org/ 10.1073/pnas.0304068101.

39. Duplouy A, Brattstrom O. Wolbachia in the genus Bicyclus: a forgotten player. Microb Ecol. 2018;75(1):255-63. https://doi.org/10.1007/s00248017-1024-9.

40. Ilinsky Y, Kosterin OE. Molecular diversity of Wolbachia in Lepidoptera: prevalent allelic content and high recombination of MLST genes. Mol Phylogenet Evol. 2017;109:164-79. https://doi.org/10.1016/j.ympev.2016.12.034.

41. Aduse-Poku K, Brakefield PM, Wahlberg N, Brattström O. Expanded molecular phylogeny of the genus Bicyclus (Lepidoptera: Nymphalidae) shows the importance of increased sampling for detecting semi-cryptic species and highlights potentials for future studies. Syst Biodivers. 2016; 15(2):215-130. https://doi.org/10.1080/14772000.2016.1226979.

42. Ackery D. Host plant untilization by African and Australian butterflies. Biol J Linn Soc. 1991:44:335-51.

43. Gupta A, Shaw M, Cardinal S, Fernandez-Triana J. A review of unusual species of Cotesia (Hymenoptera, Braconidae, Microgastrinae) with the first tergite narrowing at midlength. Zookeys. 2016;580:29-44. https://doi.org/10. 3897/zookeys.580.8090. 
44. Wu SF, Sun FD, Qi YX, Yao Y, Fang Q, Huang J, et al. Parasitization by Cotesia chilonis influences gene expression in fatbody and hemocytes of Chilo suppressalis. PLoS One. 2013;8(9):e74309. https://doi.org/10.1371/ journal.pone.0074309.

45. Fox EGP, Bressan-Nascimento S. Biological characteristics of Evania appendigaster (L.) (Hymenoptera: Evaniidae) in different densities of Periplaneta americana (L.) oothecae (Blattodea: Blattidae). Biol Control. 2006; 36(2):183-8. https://doi.org/10.1016/j.biocontrol.2005.09.006.

46. Van Borm S, Wenseleers T, Billen J, Boomsma JJ. Cloning and sequencing of wsp encoding gene fragments reveals a diversity of co-infecting Wolbachia strains in Acromyrmex leafcutter ants. Mol Phylogenet Evol. 2003;26(1):102-9. https://doi.org/10.1016/s1055-7903(02)00298-1.

47. Rasgon JL, Gamston CE, Ren X. Survival of Wolbachia pipientis in cell-free medium. Appl Environ Microbiol. 2006;72(11):6934-7. https://doi.org/10. 1128/AEM.01673-06.

48. Yapo ML, Tuo Y, Kone M, Kouassi P. Diversity of butterflies visitors of cashew (Anacardium occidentale L.) flowers in Korhogo (Northern Côte d'ivoire). Int J Entomol Res. 2018;3(3):7-10.

49. Kudom AA, Kofi KP. Floral visitors of Ananas comosus in Ghana: a preliminary assessment. J Pollination Ecol. 2010;2(5):27-32. https://doi.org/ 10.26786/1920-7603(2010)4.

50. Gerth M, Gansauge MT, Weigert A, Bleidorn C. Phylogenomic analyses uncover origin and spread of the Wolbachia pandemic. Nat Commun. 2014; 5:5117. https://doi.org/10.1038/ncomms6117.

51. Bailly-Bechet M, Martins-Simoes P, Szollosi GJ, Mialdea G, Sagot MF, Charlat S. How long does Wolbachia remain on board? Mol Biol Evol. 2017;34(5): 1183-93. https://doi.org/10.1093/molbev/msx073.

52. Saridaki A, Bourtzis K. Wolbachia: more than just a bug in insects genitals. Curr Opin Microbiol. 2010;13(1):67-72. https://doi.org/10.1016/j. mib.2009.11.005

53. Detcharoen M, Arthofer W, Schlick-Steiner BC, Steiner FM. Wolbachia megadiversity: $99 \%$ of these microorganismic manipulators unknown. FEMS Microbiol Ecol. 2019;95(11). https://doi.org/10.1093/femsec/fiz151.

54. Bleidorn C, Gerth M. A critical re-evaluation of multilocus sequence typing (MLST) efforts in Wolbachia. FEMS Microbiol Ecol. 2018;94(1). https://doi.org/ 10.1093/femsec/fix163.

55. Gerth M, Bleidorn C. Comparative genomics provides a timeframe for Wolbachia evolution and exposes a recent biotin synthesis operon transfer. Nat Microbiol. 2016;2:16241. https://doi.org/10.1038/ nmicrobiol.2016.241.

56. LePage DP, Metcalf JA, Bordenstein SR, On J, Perlmutter JI, Shropshire JD, et al. Prophage WO genes recapitulate and enhance Wolbachia-induced cytoplasmic incompatibility. Nature. 2017;543(7644):243-7. https://doi.org/ 10.1038/nature21391.

57. O'Neill SL, Giordano R, Colbert AME, Karr TL. $16 \mathrm{~S}$ rRNA phylogenetic analysis of the bacterial endosymbionts associated with cytoplasmic incompatibility in insects. Proc Natl Acad Sci. 1992;89:2699-702. https://doi.org/10.1073/ pnas.89.7.2699

58. Rousset F, Bouchon D, Pintureau B, Solignac M. Wolbachia endosymbionts responsible for various alterations of sexuality in arthropods. Proc Biol Sci. 1992;250(1328):91-8. https://doi.org/10.1098/rspb.1992.0135.

59. Olson DM, Dinerstein E, Wikramanayake E, Burgess ND, Powell GVN, Underwood EC, et al. Terrestrial ecoregions of the world: a new map of life on earth. BioScience. 2001;51:933-8.

60. Olson DM, Dinerstein E. The global 200: a representation approach to conserving the earth's most biologically valuable ecoregions. Conserv Biol. 1998;12:502-15.

61. Halali S, Brakefield PM, Collins SC, Brattstrom O. To mate, or not to mate: the evolution of reproductive diapause facilitates insect radiation into African savannahs in the Late Miocene. J Anim Ecol. 2020;89(5):1230-41. https://doi.org/10.1111/1365-2656.13178.

62. Zhou W, Rousset F, O'Neil S. Phylogeny and PCR-based classification of Wolbachia strains using wsp gene sequences. Proc Biol Sci. 1998;265(1395): 509-15. https://doi.org/10.1098/rspb.1998.0324.

63. Kearse M, Moir R, Wilson A, Stones-Havas S, Cheung M, Sturrock S, et al. Geneious basic: an integrated and extendable desktop software platform for the organization and analysis of sequence data. Bioinformatics. 2012;28(12): 1647-9. https://doi.org/10.1093/bioinformatics/bts199.

64. Miller MA, Pfeiffer W, Schwartz T. Creating the CIPRES Science Gateway for inference of large phylogenetic trees. In: Proceedings of the Gateway
Computing Environments Workshop (GCE). New Orleans: 2010. p. 1-8. https://doi.org/10.1109/GCE.2010.5676129.

65. Stamatakis A. RAxML version 8: a tool for phylogenetic analysis and postanalysis of large phylogenies. Bioinformatics. 2014;30(9):1312-3. https://doi. org/10.1093/bioinformatics/btu033.

66. Letunic I, Bork P. Interactive tree of life (iTOL) v4: recent updates and new developments. Nucleic Acids Res. 2019;47(W1):W256-W9. https://doi.org/10. 1093/nar/gkz239.

67. Letunic I, Bork P. Interactive tree of life (iTOL): an online tool for phylogenetic tree display and annotation. Bioinformatics. 2007;23(1):127-8. https://doi.org/10.1093/bioinformatics/btl529.

\section{Publisher's Note}

Springer Nature remains neutral with regard to jurisdictional claims in published maps and institutional affiliations.
Ready to submit your research? Choose BMC and benefit from:

- fast, convenient online submission

- thorough peer review by experienced researchers in your field

- rapid publication on acceptance

- support for research data, including large and complex data types

- gold Open Access which fosters wider collaboration and increased citations

- maximum visibility for your research: over $100 \mathrm{M}$ website views per year

At BMC, research is always in progress.

Learn more biomedcentral.com/submissions 